\title{
sensors
}

ISSN 1424-8220

(C) 2002 by MDPI

http://www.mdpi.net/sensors

\section{Ion Selective PVC Membrane Electrode for the Determination of Methacycline Hydrochloride in Pharmaceutical Formulation}

\author{
Hassan Y. Aboul-Enein ${ }^{1 *}$, Xian Xiang Sun ${ }^{2}$ and Cheng Jun Sun ${ }^{3}$ \\ ${ }^{1}$ Pharmaceutical Analysis Laboratory Biological and Medical Research Department, MBC-03-65, \\ King Faisal Specialist Hospital \& Research Center, P.O. Box 3354, Riyadh 11211, Saudi Arabia \\ ${ }^{2}$ Department of Chemical Engineering, Jiangsu Institute of Petrochemical Technology, Changzhou \\ 213016, Peoples Republic of China \\ ${ }^{3}$ P.O. Box 1048, Beijing 102205, Peoples Republic of China \\ * Author to whom correspondence should be addressed. E-mail: enein@kfshrc.edu.sa
}

Received: 10 May 2002 / Accepted: 15 May 2002 / Published: 18 October 2002

\begin{abstract}
A plastic membrane electrode for the determination of methacycline hydrochloride was fabricated based on the use of methacycline-tetraphenylborate as the electroactive substance, and dioctylphtalate as the plasticizing agent. It was found that the potential responses of the electrode were influenced by $\mathrm{pH}$ of the tested solution when $\mathrm{pH}>3$. Under the condition of $\mathrm{pH} 2.6$, the linear response range, slope $\left(25^{\circ} \mathrm{C}\right)$ and detection limit obtained were $3.0 \times 10^{-2} \sim 6.0 \times 10^{-6} \mathrm{M}, 52.9 \mathrm{mv}$ per decade and $3.4 \times 10^{-6} \mathrm{M}$, respectively. The response time of the electrodes was $<15$ seconds. The values of recovery obtained were 99.2 101.2\%. The electrode was successfully applied to determination of methacycline hydrochloride in tablet by direct potentiometric method. The result obtained with the electrode was in good agreement with the value obtained by using the official method (highperformance liquid chromatography).
\end{abstract}

Keywords: Ion-selective electrode; Potentiometry; Methacycline; Drug analysis

\section{Introduction}

Tetracyclines are widely used as broad spectrum antibiotics for high activity against nearly all gram-positive and gram-negative bacteria. Moreover, it is found that tetracyclines could be applied to diagnosis and therapeutics of carcinomas [1]. Therefore, the study of analytical methods for 
determination of tetracyclines has been a noticeable project in the field of drug analysis [2-7].

Methacycline hydrochloride (MC.Cl), 4-(dimethylamino)-1,4,4a,5,5a,6,11,12a-octahydro3,5,10,12,12a-pentahydroxy-6-methylene-1,11-dioxo-2-naphthacenecarboxamide monohydrochloride, is an intermediate during the synthesis of oxytetracycline, and possesses higher activity against the bacteria in comparison to tetracycline and oxytetracycline. For the determination of methacycline hydrochloride, high performance liquid chromatography [8] and antibiotics-microbial assay [9] were recommended in some pharmacopoeias. Only few studies on the method for determination of methacycline(MC) in pharmaceutical analysis are reported, including high performance liquid chromatography [10], spectrophotometry [11], phosphorimetry [12] and thin-layer chromatography [13-14]. Ion-selective electrodes are playing an important role in pharmaceutical analysis [15-17] due to its simplicity, rapidity and accuracy over some other analytical methods. Recently, it is realized to show dramatically improved detection limits, which can only be achieved by using any other electrochemical technologies [18]. To the best of our knowledge, however, no methacycline ionselective membrane electrode has been reported. In present paper, a methacycline ion-selective PVC membrane electrode is developed based on the use of ion-pair compound of methacyclinetetraphenylbroate (MC-TPB) as the electroactive substance, and dioctylphthalate(DOP) used as plasticizer. The performances of the electrode along with the other related methacycline-selective electrodes which were fabricated by using the respective ion-pair compounds,methacyclinesilicotungstate (MC-SiT) and methacycline-phosphotungatate (MC-PT), as the corresponding electroactive substance in the membrane are investigated experimentally, and the proposed electrode was successfully applied for the determination of $\mathrm{MC} . \mathrm{Cl}$ in the pharmaceutical tablet formulations.

\section{Experimental}

\section{Reagents}

Sodium tetraphenylborate, phosphotungstic acid, silicotungstic acid were commercially available (Fluka, Buchs, Switzerland). Dioctyl phthalate (DOP), dibutyl phthalate (DBP), poly (vinyl chloride) (PVC) of relatively high molecular weight were used. Methacycline hydrochloride (MC.Cl) was obtained in the pure raw material, which was of Chinese pharmacopoeia grade [8], and the pharmaceutical formulation from a local pharmaceutical company. All the reagents and solvents were of analytical reagent grade. Deionized water was used throughout the study.

Diluted hydrochloride acid ( $\mathrm{pH}$ 2.6) was prepared which was used as a background solution for preparation of standard solution of $\mathrm{MC} . \mathrm{Cl}$ or sample solutions.

A $0.1 \mathrm{M}$ stock solution of $\mathrm{MC} . \mathrm{Cl}$ was prepared by dissolving the appropriate, accurate amount of the pure drug in the background solution. A $1.0 \times 10^{-2} \sim 1.0 \times 10^{-6} \mathrm{M}$ solution of $\mathrm{MC}$.Cl were prepared daily by sequential dilution of the appropriate stock solution with the background solution. All solutions of $\mathrm{MC} . \mathrm{Cl}$ were kept in brown bottles.

\section{Preparation of Ion-pair Compound}

Ion-Pair Compound of Methacycline - Tetraphenylborate (MC-TPB): About $20 \mathrm{~mL}$ of $0.01 \mathrm{M}$ 
solution of $\mathrm{MC}$ was mixed with $25 \mathrm{~mL}$ of $0.01 \mathrm{M}$ solution of tetraphenylborate under stirring. The resulting precipitates were filtered off, washed with water, dried at $60^{\circ} \mathrm{C}$.The preparation of the ionpair compound, methacycline-silicotungstate (MC-SiT), was conduced with the similar procedures but using $0.01 \mathrm{M}$ silicotungestic acid.

Ion-Pair compound of Methacycline -Phosphotungstate: The preparation of methacyclinephosphotungstate(MC-PT) was carried out by mixing the two solutions at the ratio of volume, $65: 20$,i.e., $65 \mathrm{~mL}$ of $0.01 \mathrm{M}$ solution of $\mathrm{MC}$ was mixed with $20 \mathrm{~mL}$ of $0.01 \mathrm{M}$ solution of PT. The other procedures are similar to the one state above. The composition of the ion-pair compound, $(\mathrm{MC})_{3} \mathrm{PT}$, was confirmed by elemental analysis data. Hereafter this ion pair compound was still represented as MC-PT.

\section{Preparation of the Electrode}

For MC-TPB electrode (electrode A), the mixture of PVC cocktail was prepared by dissolving $0.5 \mathrm{mg}$ of MC-TPB, $31.5 \mathrm{mg}$ of PVC, $68.0 \mathrm{mg}$ of DOP in $2.5 \mathrm{~mL}$ of tetrahydrofuran. The sensing membrane was prepared by pouring the mixture onto a glass dish (ca.4cm diameter) and allowed to dry at room temperature. The cocktails and sensing membranes for both MC-SiT electrode (electrode B) and MC-PT electrode (electrode C) were prepared analogously, the compositions of the sensing membrane prepared were $1.0 \mathrm{wt} \% \mathrm{MC}-\mathrm{SiT}, 57.2 \mathrm{wt} \% \mathrm{DOP}, 41.8 \mathrm{wt} \%$ of PVC for the electrode B, and $10.0 \mathrm{wt} \%$ of MC-PT, $45.0 \mathrm{wt} \%$ of DBP, $45.0 \mathrm{wt} \%$ of PVC for the electrode C, respectively.

The PVC membrane electrodes were constructed using similar procedures described previously [19]. A membrane (ca.16-mm diameter) was cut out and glued to the polished end of a PVC tube by using a PVC (ca. 5 wt \% )- THF solution. The $\mathrm{Ag}-\mathrm{AgCl}$ electrode and $1.0 \times 10^{-3} \mathrm{M}$ of $\mathrm{MC}$.Cl solution were used as the reference electrode and the internal filling solution of electrode, respectively.

The assembled electrodes were conditioned by soaking into $1.0 \times 10^{-3} \mathrm{M}$ of methacycline hydrochloride solution for $2 \mathrm{~h}$ before the use of electrodes. When not in use, the electrodes were stored in air.

\section{Measurement of Electromotive Force (emf)}

A methacycline-selective PVC electrode and a saturated calomel electrode(SCE) were used as the indicating electrode and the reference electrode, respectively. The emf measurements were carried out at room temperature with a Model $\mathrm{pHs}-2$ precision $\mathrm{pH}-$ meter in the following cell:

\section{S.C.E. / test solution / ISE}

The test solution were constantly stirred with magnetic stirring.

\section{Analytical Method for Pharmaceutical Formulation}

Two methacycline hydrochloride tablets were weighted accurately, crushed and mixed in a mortar, and dissolved in $30 \mathrm{~mL}$ of the background solution under stirring condition. The solution was transferred into a 50-mL volumetric flask, then completed to the mark with the background solution. 5 $\mathrm{mL}$ of this solution was taken and transferred into an another 50 - $\mathrm{mL}$ volumetric flask, completed to 
volume with the background solution. The methacycline selective PVC membrane electrode and the reference electrode were immersed into the test solution. The content of MC in the tablets was determined by using the direct potentiometric method.

\section{Results and Discussion}

\section{Optimization of the Membrane Composition}

In the previous experimental investigations [19-21], it is obvious that both kind of plasticizer selected and the membrane composition used can influence the response performances (such as the sensitivity, linear concentration range, the detection limit, the response time etc.) of a PVC membrane ion-selective electrode, if other properties of the electrode, e.g. selectivity or the $\mathrm{pH}$ response, are omitted. In this study, three plasticizers, DOP, DBP and DNP, were used to examine the optimization of the membrane with plasticizer entailed the use of plasticizer content (ratio) of 60.0,64.0,68.0 wt \%, and the use of PVC contents of 39.0,35.0, and $30.0 \mathrm{wt} \%$. The electroactive compound (MC-TPB) contents of $0.5,1.0,1.5 \mathrm{wt} \%$ were used and the sum of percentage for the three components was adjusted to $100 \%$.The results obtained showed that the response performances of the electrode prepared were rather different depending on the use of plasticizer, the proportion of the plasticizer toward PVC and of the electroactive compound. The typical potential responses of the electrodes constructed with three plasticizers were given in Figure 1. As shown in Fig.1, the DOP-PVC electrodes were superior to DBP- and DNP- PVC electrodes in both the response slope and linear concentration range. So DOP was selected as the plasticizer of liquid membrane electrode. The best membrane composition of the DOP-PVC electrode was 31.5(w/w) \% DOP,67.8(w/w) \% PVC and 0.7(w/w) \% ion-pair which is used in this study.

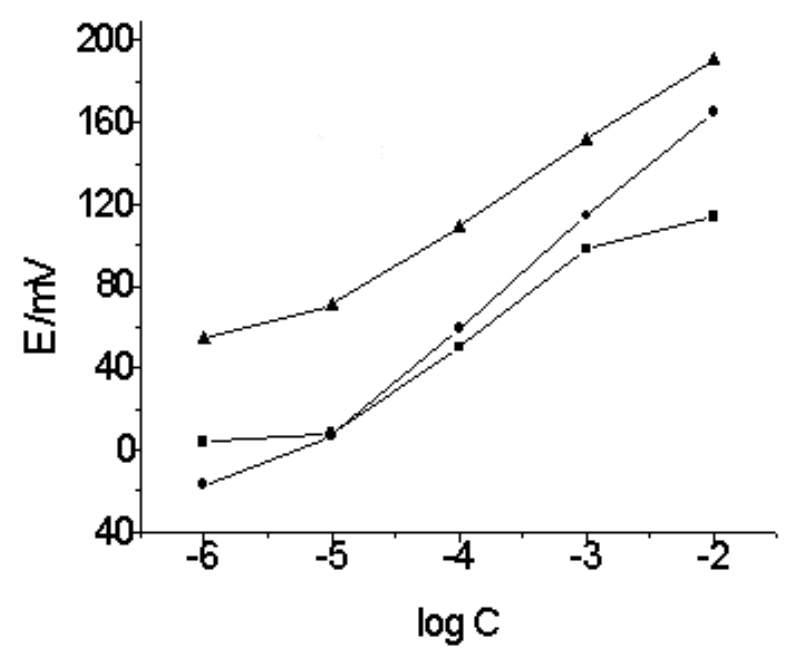

Figure 1. Optimization of plasticizers. $\mathrm{DBP}(\boldsymbol{\square})$ (the PVC membrane composition: DBP 64.0 wt \%, PVC 34.5 wt \%, MC-TPB 1.5wt\%);DOP(•) (DOP $68.0 \mathrm{wt} \%$, PVC $31.5 \mathrm{wt} \%$, MC-TPB $0.5 \mathrm{wt} \%) ; \mathrm{DNP}(\boldsymbol{\Delta})(\mathrm{DNP} 60.0 \mathrm{wt} \%$, PVC $39.0 \mathrm{wt} \%$, MC-TPB $1.0 \mathrm{wt} \%)$. 


\section{Response Characteristics of Electrode}

The response characteristics of the MC-TPB electrode (electrode A), MC-SiT electrode (electrode B) and MC- PT electrode (electrode C) are summarized in Table 1 and shown in Figure 2. As can be seen, the potential response of the proposed electrode (electrode A) at varying concentration of methacycline hydrochloride displays the widest linear response range toward $\mathrm{MC}$, being in the concentration range of $6.0 \times 10^{-6}$ to $3.0 \times 10^{-2} \mathrm{M}$ with a Nernstian slope of $52.9 \pm 0.2 \mathrm{mV}$ per decade. The limit of detection was $3.4 \times 10^{-6} \mathrm{M}$. All the electrodes show a very short response time $(\leq 15 \mathrm{~s})$ over a MC concentration range of $1.0 \times 10^{-1}$ to $1.0 \times 10^{-4} \mathrm{M}$. The stability of electrode A was monitored continuously at $1.0 \times 10^{-3} \mathrm{M}$ of $\mathrm{MC}$ solution and evaluated for a period of $6 \mathrm{~h}$, the potential drift obtained was $\leq 0.13 \mathrm{mV} / \mathrm{h}$.

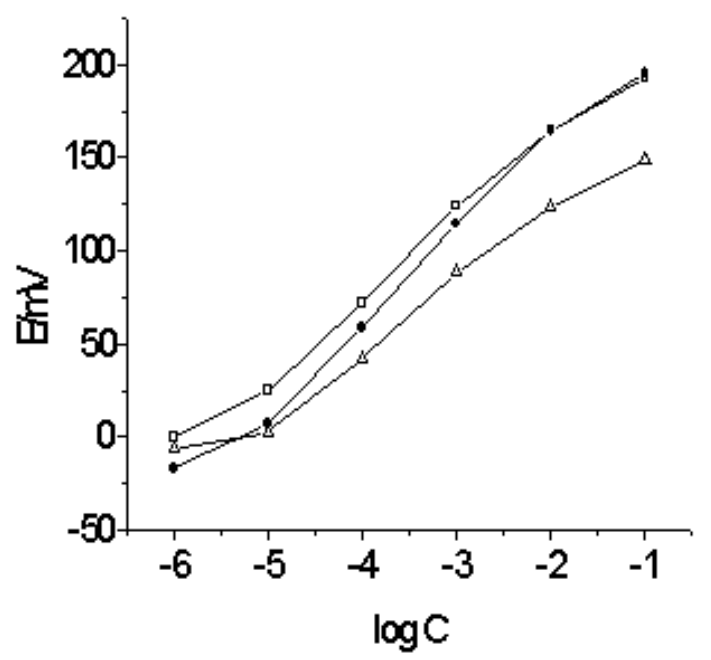

Figure 2. Calibration curves of the electrodes. Electrode $\mathrm{A}(\bullet)$; Electrode $\mathrm{B}(\square)$;Electrode $\mathrm{C}(\Delta)$.

The repeatability of the potential reading for electrode A was examined by subsequent measurements in $1.0 \times 10^{-3} \mathrm{M}$ of MC solution immediately after measuring the first set of solution at $1.0 \times 10^{-4} \mathrm{M}$ of MC solution. The standard deviations of measuring emf for 5 replicate measurements obtained are $0.20 \mathrm{mV}$ for the solution of $1.0 \times 10^{-4} \mathrm{M}$ and $0.11 \mathrm{mV}$ for the solution of $1.0 \times 10^{-3} \mathrm{M}$. This means that the repeatability of potential response of the electrode is good. The response properties of the proposed electrode did not change obviously after the use of the electrode for two months.

Table 1. Response Characteristics of the Electrodes.

\begin{tabular}{|l|c|c|c|}
\hline Parameter & Electrode A & Electrode B & Electrode C \\
\hline Slope (mV per decade) & 52.9 & 50.2 & 46.5 \\
\hline Linearity range (M) & $3.0 \times 10^{-2} \sim 6.0 \times 10^{-6}$ & $5.0 \times 10^{-3} \sim 1.0 \times 10^{-5}$ & $6.0 \times 10^{-3} \sim 2.0 \times 10^{-5}$ \\
\hline Correlation coefficient & 0.9998 & 0.9995 & 0.9874 \\
\hline Detection limit (M) $^{\text {Response time }}{ }^{\text {(s) }}$ & $3.4 \times 10^{-6}$ & $3.4 \times 10^{-6}$ & $1.0 \times 10^{-5}$ \\
\hline
\end{tabular}

${ }^{\mathrm{a}}$ The concentration ranges of $\mathrm{MC}$ tested were $1.0 \times 10^{-1} \sim 1.0 \times 10^{-4} \mathrm{M}$. 


\section{Effect of $p H$}

The effects of $\mathrm{pH}$ on the responses of the electrodes were examined by measuring the potential variation in the emf over the $\mathrm{pH}$ range of 1.0-11.5 and the results were shown in Fig. 3. For the electrode $\mathrm{A}$, as can be seen, the smaller changes in the potentials occurred in the $\mathrm{pH}$ ranges of both 2.0-3.0 and 5.0-6.0, beyond which the change of the potential was considerable. It is known that tetracyclines are unstable due to either forming the isomeric compounds containing inner ether at basic solution or undergo dehydration at acidic solution $(\mathrm{pH}<2$ ) [20] .So a $\mathrm{pH}$ range of 2.0-3.0 can be used as the $\mathrm{pH}$ working range for the methacycline-selective electrode. To enable a simple measurement protocol and keep the $\mathrm{pH}$ value of all the test solutions within the desired range ( $\mathrm{pH} 2.0-3.0)$, as those of methacycline hydrochloride standard solutions, a diluted hydrochloric acid at which a $\mathrm{pH}$ value is fixed between 2.0-3.0 was used as the background solution in this study. It is obvious that the advantage of the background solution used eliminate the $\mathrm{pH}$ adjustment.

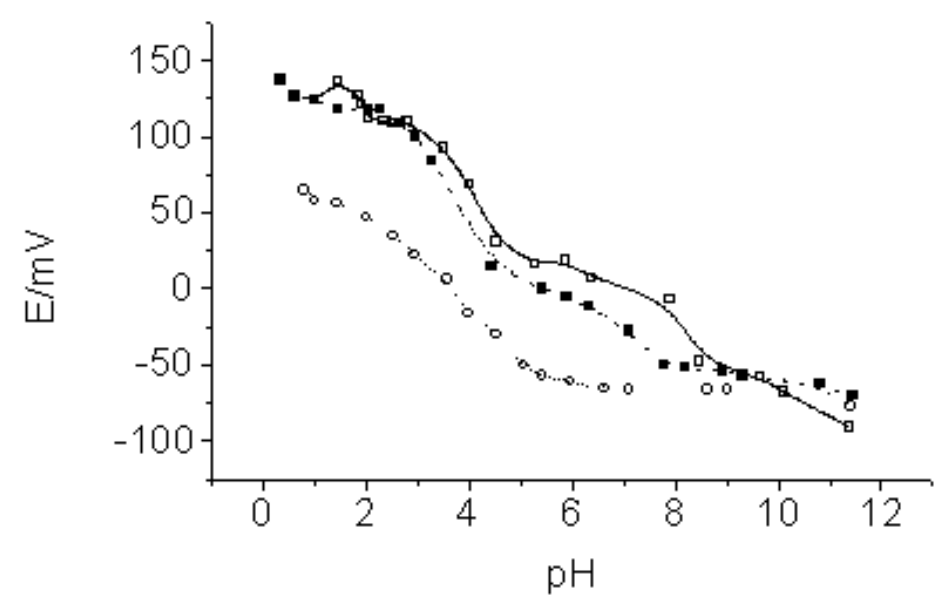

Figure 3. Effect of $\mathrm{pH}$ on the potential of the electrode. Electrode $\mathrm{A}(\square)$; Electrode $\mathrm{B}(\mathbf{\square})$; Electrode $\mathrm{C}(\mathrm{O})$.

\section{Selectivity of the Electrode}

The selectivities of electrodes were investigated by the separate solution method $\left(a_{i}=a_{j}=10^{-3} M\right)$ and the potentiometric selective coefficients, which were calculated by the similar equation as described previously [21], summarized in Table 2. As be seen from Table 2, the inorganic cations such as $\mathrm{K}^{+}, \mathrm{Na}^{+}, \mathrm{Ca}^{2+}, \mathrm{Mg}^{2+}$ etc. and the organic compounds tested, citric acid and L-glutamic acid do not interfere. Moreover, the excipients, such as corn starch, gelatin, magnesium stearate etc., in the methacycline hydrochloride tablets do not interfere with the determination of methacycline. In addition, it is also seen that the electrode B possesses the better selectivity over the other electrodes (see Table 2). This attributed probably to the large difference in the mobilities and permeabilities of the ions in MC-SiT electrode membrane as compared to the primary ion (MC.Cl). 
Table 2. Selectivity Coefficients of Electrodes.

\begin{tabular}{|l|c|c|c|}
\hline \multirow{2}{*}{ Interfering species $(\mathbf{j})$} & \multicolumn{3}{|c|}{ Log $\mathbf{K}^{\mathbf{p o t}} \mathbf{\text { MC, } \mathbf { j }}$} \\
\cline { 2 - 4 } & Electrode A & Electrode B & Electrode C \\
\hline $\mathrm{Na}^{+}$ & 1.01 & 2.02 & 1.12 \\
\hline $\mathrm{K}^{+}$ & 1.11 & 2.20 & 1.32 \\
\hline $\mathrm{NH}_{4}^{+}$ & 1.11 & 2.31 & 1.49 \\
\hline $\mathrm{Ca}^{2+}$ & 2.49 & 3.72 & 2.60 \\
\hline $\mathrm{Mg}^{2+}$ & 2.50 & 3.80 & 2.20 \\
\hline $\mathrm{Al}^{3+}$ & 2.80 & 3.89 & 2.72 \\
\hline Citric acid & 1.12 & 2.32 & 1.20 \\
\hline L-Glutamic acid & 1.15 & 2.32 & 1.02 \\
\hline
\end{tabular}

\section{Analytical Application of the Electrode}

With the electrode A, accuracy of the proposed method for determination of methacycline hydrochloride was assessed by determining 95 385 $\mu \mathrm{g} / \mathrm{mL}$ methacycline hydrochloride solutions using the direct potential method and the data obtained showed in Table 3 which indicates the average recovery and standard deviation to be $99.8 \%$ and $0.8 \%$, respectively. The direct potential method was applied to the determination of methacycline hydrochloride in pharmaceutical tablets (ca.100mg methacycline hydrochloride/tablet, Huai Yin Pharmaceutical Works, batch number: 20000113B) and compared with the pharmacopoeia method (High-performance liquid chromatography) [8]. The mean value and the relative standard deviation obtained by using methacycline selective PVC membrane electrode method was $96.1 \mathrm{mg} /$ tablet and $0.5 \%(\mathrm{n}=6)$ respectively while the mean value obtained with the pharmacopoeia method was $96.4 \mathrm{mg} /$ tablet.

Table 3. Recovery of Metacycline Hydrochloride.

\begin{tabular}{|c|c|c|}
\hline Added $^{\mathbf{a}}$ / $\mathbf{~ m g ~}$ & Found $^{\mathbf{b}}$ / $\mathbf{m g}$ & Recovery $^{\mathbf{c}}$ / \% \\
\hline 4.79 & 4.78 & $99.8 \pm 0.6$ \\
\hline 9.58 & 9.54 & $99.6 \pm 0.8$ \\
\hline 19.16 & 19.15 & $99.9 \pm 1.1$ \\
\hline
\end{tabular}

${ }^{\text {a }}$ Total volume of the tested solutions was $50.0 \mathrm{~mL}$.

${ }^{\mathrm{b}}$ Average of five determinations.

${ }^{c}$ Mean of recoveries \pm standard deviation.

\section{Conclusion}

A Methacycline-selective PVC membrane electrode based on the ion-pair compound of MC-TPB and DOP as plasticizer was developed. Its linear range, slope and limit of detection were $3.0 \times 10^{-}$ ${ }^{2} \sim 6.0 \times 10^{-6} \mathrm{M}, 52.9 \mathrm{mV}$ per decade and $3.4 \times 10^{-6} \mathrm{M}$, respectively. The effect of $\mathrm{pH}$ on the potential response indicated that larger influence of $\mathrm{pH}$ occurred when $\mathrm{pH}$ of the solution was in the range of 3 5. The response properties of electrodes based on the ion-pair compounds, MC-PT and MC-SiT, were also investigated experimentally. The linear range of $\mathrm{MC}$ concentration for electrode constructed 
with the ion-pair compound MC-TPB was wider than that of electrodes based on the ion-pair compound MC-PT or MC-SiT. The proposed electrode was successfully applied to the determination of methacycline hydrochloride in pharmaceutical preparation. The analytical method proposed proved to be a simple, rapid and accurate method.

\section{Acknowledgement}

One of authors (X.X. Sun) thank the department of education of Jiangsu Province for the financial support of this work. Also the author (H.Y.A.-E) would like to thank the administration of King Faisal Specialist Hospital and Research Centre for its support for the Pharmaceutical Analysis Laboratory research program.

\section{References}

1. Lu, J.; Zhao, P.; Zhan, G.; Sun, Y.; Wang, Y.; Ho, X.; Shi, H. Fenxi Kexue Xuebao 1998, 14, 19.

2. Lopez, Paz, J.L.; Martinez Calatayud, J. J.Pharm.Biomed.Anal. 1993, 11, 1093.

3. Espinosa-Mansilla, A.; Salinas, F.; De Orbe Paya, I. Anal.Chim.Acta 1995, 313, 103.

4. Oungpipat, W.; Southwell-Keely, P.; Alexander, P.W. Analyst 1995, 120, 1559.

5. Croubeks, S.; Vermeersch, H.; De Backeer, P.; Ssantos, M.D.F.; Remon, J.P.; van Peteyhem, C. J. Chromatogr., B,Biomed.Appl. 1998, 708, 145.

6. Farin, D.; Piva, G.; Gozlan, I.; Kitzes, R. Chromatographia 1998, 47, 547.

7. Liu, W.H.; Wang, Y.; Tang, J.H.; Shen, G.L.; Yu, R.Q. Analyst 1998, 123, 365.

8. Chinese Pharmacopoeia, Part II (2000), pp.652.

9. U.S.Pharmacopoeia, XXIII, (1995), pp.968.

10. Bryan, P.D.; Stewart, J.T. J. Pharm.Biomed. Anal. 1994, 12, 675.

11. Saha, U.; Sen, A.K.; Das, T.K.; Bhowal, S.K. Talanta 1990, 37, 1193.

12. Xie, H.Z.; Dong, C.A.; Jin, W.J.; Wei, Y.S.; Liu, C.S.; Zhang, S.S.; Zhou, B.L. Anal.Chim.Acta 1996, 319, 239.

13. Liu, L.J.; Yaowu Fenxi Zazhi 1993, 13, 318.

14. Naidon, W.; Hua, S.; Roets, E.; Hoogmartens, J. J.Planar Chromatogr. Mod. TLC 1994, 7, 297.

15. Vytras, K. J. Pharm. Biomed. Anal. 1989, 7, 789.

16. Cosofret, V.V. Trends in Anal.Chem. 1991, 10, 298.

17. Stefan, R.I.; Baiulescu, G.E.; Aboul-Enein, H.Y. Trends in Anal.Chem. 1997, 27, 307.

18. Bakker, E.; Pretsch, E; Qin,W. Chinese Sensors (Chinese) 2001, 21, 1.

19. Sun, X.X.; Ding, H.L. Fenxi Shiyanshi 1999, 18, 75.

20. An, D.K. Yaowu Fenxi (Chinese). Chinese People Hygene's Publishing House, Beijing, 1986, pp. 227-228.

21. Aboul-Enein, H.Y.; Sun, X.X. Analusis 2000, 28, 855.

Sample Availability: Available from the authors.

(C) 2002 by MDPI (http://www.mdpi.net). Reproduction is permitted for noncommercial purposes. 